Short Note

\title{
Eleven Novel Polymorphic Microsatellite Loci for Oval Squid Sepioteuthis Lessoniana (Shiro-Ika Type)
}

\author{
Satoshi Tomano ${ }^{1}$, Kamarudin Ahmad-Syazni ${ }^{1}$, Yukio Ueta ${ }^{2}$, Kenichi Ohara ${ }^{3}$ \\ and Tetsuya Umino ${ }^{1, *}$
}

1 Graduate School of Biosphere Science, Hiroshima University, Higashi-Hiroshima, Hiroshima 739-8528, Japan; E-Mails: m121065@hiroshima-u.ac.jp (S.T.); d113199@hiroshima-u.ac.jp (K.A.-S.)

2 Tokushima Agriculture, Forestry and Fisheries Technology Support Center, Naruto, Tokushima 771-0361, Japan; E-Mail: ueta_yukio_2@pref.tokushima.lg.jp

3 Gifu Prefectural Research Institute for Freshwater Fish and Aquatic Environments, Gero, Gifu 509-2592, Japan; E-Mail: ohara-kenichi@pref.gifu.lg.jp

* Author to whom correspondence should be addressed; E-Mail: umino@hiroshima-u.ac.jp; Tel.: +81-824-247-944; Fax: +81-824-247-944.

Received: 9 August 2013; in revised form: 5 September 2013 / Accepted: 25 September 2013 / Published: 8 October 2013

\begin{abstract}
The oval squid Sepioteuthis lessoniana is one of the most economically important squid species in Japan; however, its population structure is poorly understood due to the lack of hypervariable markers. Such information is critical for managing sustainable fisheries, as well as for ensuring the existence of wild $S$. lessoniana stocks. Eleven candidate microsatellite loci were isolated from a small insert genomic DNA library. Polymorphisms in these 11 loci were screened in 24 wild individuals. The number of alleles per locus was found to range from 5 to 19 alleles, and the observed heterozygosity ranged from 0.292 to 0.958 . No evidence for linkage disequilibrium was detected among all the loci. The genotypic proportions conformed to Hardy-Weinberg equilibrium, except at one locus. In conclusion, these polymorphic microsatellite loci may be used to develop a genetic framework to manage $S$. lessoniana in the future.
\end{abstract}

Keywords: microsatellite loci; oval squid; genetic structure; Sepioteuthis lessoniana 


\section{Introduction}

The oval squid Sepioteuthis lessoniana, a member of the Loliginidae family, is distributed over a broad geographical range throughout the Indo-Pacific region, including northern Australia, central Japan, and eastward to the Hawaiian Islands [1]. In Japan, oval squids are abundant in inshore waters along the coast of western Japan and are one of the most economically important squid species in neritic fisheries.

Using allozyme markers, Izuka et al. [2] previously concluded that the population structure of S. lessoniana around mainland Japan is homogenous, in agreement with the observations of Aoki et al. [3] based on the sequencing analysis of the non-coding region of mitochondria. However, with the use of allozyme markers, Yokogawa and Ueta [4] also found evidence for differentiation between the Pacific Ocean and the Japan Sea populations. To date, the population structure of S. lessoniana over the primary biogeographic range in Japan remains unclear. A thorough understanding of the appropriate conservation units is a critical first step in addressing the fishery management of $S$. lessoniana; therefore, there is a need to identify hypervariable microsatellite loci of the species for allowing accurate evaluation of its genetic population structure.

Some researchers have proposed that $S$. lessoniana in southwest Japan is a species complex consisting of "Aka-ika", "Shiro-ika", and "Kuwa-ika" types that exhibit phenotypic and genotypic differences [5]. In the present study, we only evaluated the "Shiro-ika" type. We believe that this study will provide powerful genetic markers not only for studying the genetic structure of the species but also for planning the management of "Shiro-ika" S. lessoniana in the future.

\section{Results and Discussion}

Twenty-four unrelated individuals were collected from Mugi, Tokushima Prefecture, and the levels of polymorphism with primer sequences and repeat motifs in the 11 microsatellite loci were evaluated (Table 1). The number of alleles per locus ranged from 5 to 19 alleles. The observed heterozygosity ranged from 0.292 to 0.958 , whereas the expected heterozygosity ranged from 0.368 to 0.947 . Among 11 microsatellite loci, the locus SL-SHIRO 16 deviated significantly $(p<0.045)$ from Hardy-Weinberg equilibrium after sequential Bonferroni correction, which is probably due to excess of homozygosity. The Micro-checker analysis [6] further reveals that SL-SHIRO 16 may be affected by null alleles. However, there was no indication of allele scoring errors caused by stuttering or large allele dropout. In addition, no evidence for linkage disequilibrium was detected among possible pairwise locus comparisons. 
Table 1. Characterization of 11 microsatellite loci for the oval squid Sepioteuthis lessoniana.

\begin{tabular}{|c|c|c|c|c|c|c|c|c|c|}
\hline Locus & Repeat & Primer sequence (5'-3') & $\begin{array}{l}\mathbf{T}_{\mathrm{A}} \\
\left({ }^{\circ} \mathbf{C}\right)\end{array}$ & $\begin{array}{l}\text { Expected } \\
\text { Size (bp) }\end{array}$ & $\mathbf{N}_{\mathbf{A}}$ & $\begin{array}{c}\text { Allele } \\
\text { Range (bp) }\end{array}$ & HO & HE & $\begin{array}{c}\text { GenBank } \\
\text { Accession No. }\end{array}$ \\
\hline SL-SHIRO 5 & $(\mathrm{CA}) 4 \mathrm{CG}(\mathrm{CA}) 5(\mathrm{CG}) 3(\mathrm{CGCA}) 3$ & $\begin{array}{c}\text { F: ACGACCTCGTCAAAAGCACT } \\
\text { R: NED-GCTCGTCACGACTCTTGAAA }\end{array}$ & 62 & 197 & 5 & $181-197$ & 0.333 & 0.368 & AB821297 \\
\hline SL-SHIRO 8 & (GT)28 & $\begin{array}{c}\text { F: CCAACTCCGAATAAAAGCAG } \\
\text { R: HEX-CTGTCACATCCGTGAAATGG }\end{array}$ & 62 & 178 & 16 & $159-193$ & 0.875 & 0.939 & AB821298 \\
\hline SL-SHIRO 10 & $(\mathrm{CA}) 4 \mathrm{TA}(\mathrm{CA}) 11$ & $\begin{array}{l}\text { F: FAM-ACAAAACGAAGGAGGGAGGT } \\
\text { R: CATCCCACCTATTTCACAGTATCA }\end{array}$ & 62 & 214 & 5 & $203-233$ & 0.667 & 0.573 & AB821299 \\
\hline SL-SHIRO 15 & (GT)26AAGAAAGAGTA(GA)7 & $\begin{array}{c}\text { F: TTCCGCAAATTTTATGTAGCA } \\
\text { R: HEX-TTCAGTCGAAATGAGGTAGCAG }\end{array}$ & 54 & 215 & 19 & $189-235$ & 0.958 & 0.947 & AB821300 \\
\hline SL-SHIRO 16 & (GTGTGA)2(GT)30 & $\begin{array}{c}\text { F: AAACCCGCCTGACTTCAGTT } \\
\text { R: HEX-GGGACTCTTCCGTGACACAT }\end{array}$ & 62 & 205 & 15 & $170-210$ & 0.292 & 0.937 & AB821301 \\
\hline SL-SHIRO 20 & (TA) 11 & $\begin{array}{c}\text { F: NED-CGAGTCGAGCCACACTGAAG } \\
\text { R: TTCGGTCACCCTCGAATAAG }\end{array}$ & 62 & 106 & 5 & $102-112$ & 0.667 & 0.624 & AB821302 \\
\hline SL-SHIRO 22 & $(\mathrm{TA}) 13$ & $\begin{array}{c}\text { F: TCACGAGTCTTGCCTCACTG } \\
\text { R: HEX-CCTATGTGACCGGTTTTGTTG }\end{array}$ & 62 & 175 & 5 & $167-175$ & 0.625 & 0.602 & AB821303 \\
\hline SL-SHIRO 23 & $(\mathrm{CTTT}) 13$ & $\begin{array}{l}\text { F: HEX-TCСTCTCTGCCACTTCCTTC } \\
\text { R: GACAAAATGAGAGGGATACGTG }\end{array}$ & 62 & 186 & 8 & $167-195$ & 0.917 & 0.872 & AB821304 \\
\hline SL-SHIRO 27 & (TATG)(TATC)30 & $\begin{array}{l}\text { F: NED-GACAAGAGGTTTATTGGCATTGA } \\
\text { R: ACCAACTCAAATAGTGTGCGTA }\end{array}$ & 54 & 112 & 13 & $101-161$ & 0.750 & 0.861 & AB821305 \\
\hline SL-SHIRO 29 & (GAAA)13 & $\begin{array}{c}\text { F: FAM-CTGGTGGAGGTGGGTGTTAC } \\
\text { R: GGGTGCCTATCTGATTGCAG }\end{array}$ & 54 & 216 & 10 & $201-233$ & 0.875 & 0.863 & AB821306 \\
\hline SL-SHIRO 30 & $(\mathrm{CA}) 12$ & $\begin{array}{c}\text { F: TGTGTAGAAATTGTCCAAACGTC } \\
\text { R: FAM-CAAGACACCAAGGTTTTATGGA }\end{array}$ & 54 & 115 & 8 & $109-129$ & 0.708 & 0.800 & AB821307 \\
\hline
\end{tabular}

$\mathrm{T}_{\mathrm{A}}$, annealing temperature; $\mathrm{N}_{\mathrm{A}}$, number of alleles; $\mathrm{HO}$, observed heterozygosity; HE, Nei's expected heterozygosity. ${ }^{*} p<0.045$, significant departure from Hardy-Weinberg expectation after sequential Bonferroni correction. 


\section{Experimental Section}

\subsection{Development of Microsatellite Markers}

To screen candidate microsatellite loci, two individuals were collected by squid jigging at Mugi, Tokushima Prefecture. A small section of the arm tissue was clipped from each specimen and stored in ethanol. DNA was subsequently extracted using the phenol-chloroform method [7], digested with Sau3AI, and directly ligated into the pUC19 vector. Ligated vector fragments were then transformed into competent Escherichia coli JM109 (Takara Bio Inc., Ohtsu, Japan). Positive colonies were detected by chemiluminescence using digoxigenin (Dig)-GT $\mathrm{GT}_{15}$ hybridization probes and the DIG Nucleic Acid Detection Kit (Boehringer, Mannheim, Germany). A total of 142 positive clones from 2352 colonies were sequenced using the ABI 3130xl Genetic Analyzer (Applied Biosystems, Foster, California, USA). Fifteen locus-specific forward and reverse primers were designed using online software Primer 3 (v. 0.4.0, Whitehead Institute for Biomedical Research, Cambridge, MA, USA) and either the forward or reverse primers were labeled at the 5' end with FAM, HEX, or NED. Of these 15 primer pairs, only 11 were able to successfully amplify fragments within expected size ranges. Consequently, these 11 loci were characterized and deposited in GenBank (accession numbers, Table 1).

\subsection{Primer Validation}

To characterize microsatellite loci, 24 individuals were collected by a set net at Mugi, Tokushima Prefecture, Japan in 2012. Genomic DNA extracted as described above was subjected to PCR in a final reaction volume of $5 \mu \mathrm{L}$, consisting of $0.7 \mu \mathrm{L}$ of $\mathrm{ddH}_{2} \mathrm{O}, 2.5 \mu \mathrm{L}$ of KOD Buffer, $1.0 \mu \mathrm{L}$ of dNTP, $0.1 \mu \mathrm{L}$ of each of forward and reverse primers $(10 \mathrm{mM}), 0.1 \mu \mathrm{L}$ of KOD Polymerase (Toyobo Co., Ltd., Osaka, Japan), and $0.5 \mu \mathrm{L}$ of the DNA template. PCR was performed in a Mastercycler Gradient 96-Well system (Eppendorf, Hamburg, Germany) with the following amplification cycle: an initial denaturing step at $94{ }^{\circ} \mathrm{C}$ for $4 \mathrm{~min}$; 30 cycles of $94{ }^{\circ} \mathrm{C}$ for $1 \mathrm{~min}$, locus-specific annealing temperatures (Table 1) for $1 \mathrm{~min}$, and $72{ }^{\circ} \mathrm{C}$ for $1 \mathrm{~min}$; and a final extension step at $72{ }^{\circ} \mathrm{C}$ for $10 \mathrm{~min}$. Next, PCR products $(1 \mu \mathrm{L})$ were mixed with $8.8 \mu \mathrm{L}$ of HiDi and $0.2 \mu \mathrm{L}$ of $400 \mathrm{HD}$ ROX Size Standard and then sequenced using an ABI 3130xl Sequencer. Allele sizes and the number of alleles were estimated using Peak Scanner software v1.0 (Applied Biosystems) and FSTAT 2.9 .3 [8], respectively. Each locus was tested for null alleles using Micro-Checker v. 2.2.3 [6]. Observed heterozygosity and expected heterozygosity were calculated using Arlequin v3.11 [9]. Other relevant parameters, including Hardy-Weinberg equilibrium and genotypic disequilibrium between pairs of loci within the population, were estimated using Genepop'007 [10].

\section{Conclusions}

The use of hypervariable microsatellite loci described in this study rendered good results when a single population was tested, suggesting that all the loci may be used for assessing the genetic diversity and the population structure of wild $S$. lessoniana, especially between the Japan Sea and Pacific Ocean. We believe that this study can not only lay a cornerstone for the investigation of accurate 
information regarding the stock structure and the recruitment source for managing sustainable S. lessoniana but also facilitate taxonomic studies of sympatric species in the future.

\section{Acknowledgments}

We would like to thank Hikosaka Tomoe for her cooperation and assistance in sequencing using the ABI 3130x1 Sequencer at the Gene Science Division, Natural Science Centre for Basic Research and Development, Hiroshima University.

\section{Conflicts of Interest}

The authors declare no conflict of interest.

\section{References}

1. Roper, C.F.E.; Sweeney, M.J.; Nauen, C.E. Cephalopods of the World. An Annotated and Illustrated Catalogue of Species of Interest to Fisheries; FAO Fisheries Synopsis: Rome, Italy, 1984; Volume 3, pp. 109-111.

2. Izuka, T.; Segawa, S.; Okutani, T. Biochemical study of the population heterogeneity and distribution of the oval squid Sepioteuthis lessoniana complex in southwestern Japan. Am. Malac. B 1996, 12, 129-135.

3. Aoki, M.; Imai, H.; Naruse, T.; Ikeda, Y. Low genetic diversity of oval squid, Sepioteuthis cf. lessoniana (Cephalopoda: Loliginidea), in Japanese waters inferred from a mitochondrial DNA non-coding region. Pac. Sci. 2008, 62, 403-411.

4. Yokogawa, K.; Ueta, Y. Genetic analysis of oval squid (Sepioteuthis lessoniana) around Japan. Venus 2000, 59, 45-55.

5. Imai, H.; Aoki, M. Genetic Diversity and Genetic Heterogeneity of Bigfin Reef Squid "Sepioteuthis lessoniana" Species Complex in Northwestern Pacific Ocean. In Analysis of Genetic Variation in Animals; Caliskan M., Ed.; InTech: Rijeka, Croatia, 2012; pp. 151-166.

6. Van Oosterhout, C.; Hutchinson, W.F.; Wills, D.P.M.; Shipley, P. Micro-Checker: Software for identifying and correcting genotyping errors in microsatellite data. Mol. Ecol. Notes 2004, 4, 535-538.

7. Sambrook, J.; Fritsch, E.F.; Maniatis, T. Molecular Cloning: A Laboratory Manual; Cold Spring Harbor Laboratory Press: Cold Spring Harbor, New York, NY, USA, 1989.

8. Goudet, J. FSTAT (version 1.2): A computer program to calculate F-statistics. J. Hered. 1995, 86, 485-486.

9. Excoffier, L.; Laval, G.; Schneider, S. Arlequin (version 3.0): An integrated software package for population genetics data analysis. Evol. Bioinform. Online 2005, 1, 47-50.

10. Rousset, F. Genepop'007: A complete reimplementation of the Genepop software for Windows and Linux. Mol. Ecol. Resour. 2008, 8, 103-106.

(C) 2013 by the authors; licensee MDPI, Basel, Switzerland. This article is an open access article distributed under the terms and conditions of the Creative Commons Attribution license (http://creativecommons.org/licenses/by/3.0/). 